\title{
Combination of Distance from Superior Mesenteric Artery and Serum CA19-9 as a Novel Prediction of Local Recurrence in Patients With Pancreatic Cancer Following Resection
}

\author{
FUMITAKE SUZUKI, YUKI FUJIWARA, RYOGA HAMURA, KOICHIRO HARUKI, \\ TARO SAKAMOTO, HIROAKI SHIBA and KATSUHIKO YANAGA \\ Department of Surgery, The Jikei University School of Medicine, Tokyo, Japan
}

\begin{abstract}
Background/Aim: Prediction of local recurrence and distant metastasis is important for patients with pancreatic cancer following pancreatic resection. The aims of this study were to identify a novel prognostic score which combines distance from common hepatic artery (CHA) or superior mesenteric artery (SMA) and examine serum CA199 for predicting local recurrence in patients with pancreatic cancer following resection. Patients and Methods: This retrospective study comprised 149 patients who went through elective pancreatic resection for pancreatic cancer between June 2007 and December, 2017. We established new scores (CHA score and SMA score) using the distance between CHA or SMA and the tumor measured by preoperative CT scan in combination with preoperative serum CA19-9 values. We evaluated the relationship between the scores and local recurrence of pancreatic cancer. Finally, we investigated the relationship between the scores and local recurrence-free survival as well as the overall survival. Results: The optimal cut-off levels of the distance between CHA or SMA and the tumor, as determined by ROC analysis, were 20.55 and $10.9 \mathrm{~mm}$, respectively. In a logistic progression model, demonstrated by multivariate analysis, lymphatic invasion $(p=0.002)$, preoperative serum CA19-9 $(p=0.007)$ and SMA score $(p=0.004)$ were identified to be independent predictors of local recurrence in patients with pancreatic cancer following resection. In a Cox progression model, demonstrated by multivariate analysis, intraoperative blood loss $(p=0.022)$, lymphatic invasion $(p=0.001)$ and SMA score $(p<0.001)$ were identified as independent factors of local
\end{abstract}

Correspondence to: Yuki Fujiwara, Department of Surgery, The Jikei University School of Medicine, 3-25-8, Nishi-Shinbashi, Minato-ku, Tokyo 105-8461, Japan. Tel: +81 334331111, e-mail: sheetan@jikei.ac.jp

Key Words: Pancreatic cancer, local recurrence, elective pancreatic resection, distance from SMA. recurrence. The independent predictors of poor overall survival by multivariate analysis consisted of intraoperative blood loss ( $p=0.045)$, intraoperative transfusion $(p=0.026)$ and SMA score $(p<0.001)$. Conclusion: The SMA score may be an independent preoperative predictor of local recurrence and prognosis in patients with pancreatic cancer.

Pancreatic cancer is one of the most fatal human malignant cancers of the digestive system and the fourth leading cause of cancer-related deaths worldwide (1). Pancreatic cancer is predicted to become the second leading cause of cancer-death in the United States by 2030 (2). Only 10-25\% of patients with pancreatic cancer are eligible for curative resection due to the lack of screening methods with high sensitivity and specificity that allow early detection $(3,4)$. The overall survival rate of patients who undergo such curative surgical resection remains poor, despite of improvements in surgical techniques, instruments, and postoperative management. Most patients will develop disease recurrence resulting in a 5-year survival of only about 10 to $25 \%$ (5-7). Well-known prognostic factors of long-term survival in patients undergoing resection of pancreatic cancer include small tumor size, absence of lymph node involvement, curative (R0) resection and adjuvant chemotherapy $(8,9)$.

The time and location pattern of cancer recurrence following pancreatic resection is unique and variable. Isolated local recurrence accounts for $30 \%$ in patients with cancer following pancreatic resection in the absence of distant metastasis $(10,11)$. Locally destructive tumor growth has been shown to be the probable cause of death in up to $30 \%$ of patients with pancreatic cancer (12). This suggests that, in addition to distant metastasis, management and prediction of local recurrence is also important to get longterm survival of patients with pancreatic cancer after resection. Unfortunately, despite the high local recurrence rate, there are no established strategies to deal with the local recurrence of pancreatic cancer. As local recurrence of pancreatic cancer is closely linked to the surgical procedure, 
the identification of risk factors for local recurrence using preoperative variables may be critical for deciding the degree of lymphadenectomy and plexus resection during pancreatic resection.

The aims of this study were to identify a novel prognostic score for predicting local recurrence in patients with pancreatic cancer using preoperative variables.

\section{Patients and Methods}

Study population. Between June 2007 and December 2017, 153 patients who underwent elective pancreatic resection for pancreatic cancer at the Department of Surgery, Jikei University Hospital in Tokyo, Japan, were retrospectively reviewed. Of these, 4 patients were excluded for lack of data or lost follow-up. We performed a retrospective review of a prospectively maintained database of patients. Of the 149 patients, 38 (25\%) were without recurrence, 44 developed local recurrence $(30.0 \%)$ and 67 developed distant metastases $(45.0 \%)$. Eight patients had both local recurrence and distant metastases, and were classified as a local recurrence group, because the primary endpoint of this study was occurrence of local recurrence. This study was approved by the Ethics Committee of the Jikei University School of Medicine (Approval number: 21-121). All patients were assessed at a preoperative disciplinary meeting and received: i) routine preoperative workups using computed tomography (CT) of the abdomen and chest, ii) endoscopic ultrasound (EUS) and iii) magnetic resonance cholangiopancreatography (MRCP). The preoperative hemogram and chemistry profile including the serum carcinoembryonic antigen (CEA) and the carbohydrate antigen 19-9 (CA19-9) were also measured in each patient. If the tumor was in the pancreatic head, endoscopic retrograde cholangiopancreatography (ERCP) was often performed for cytology or obstructive jaundice.

Perioperative management and follow-up following elective pancreatic resection. All patients underwent pacreaticoduodenectomy (PD) $(n=92)$, distal pancreatectomy (DP) $(n=51)$ or total pancreatectomy (TP) $(n=6)$ with lymphadenectomy, depending on the location of the pancreatic tumor. Twenty-two patients went through portal vein resection and reconstruction. To accomplish radical lymphadenectomy, common hepatic artery (CHA), proper hepatic artery (PHA), left hepatic artery (LHA), right hepatic artery (RHA), common bile duct and portal vein in the hepatoduodenal ligand were skeletonized, and the right-side plexus of the superior mesenteric artery (SMA) was dissected in case of pancreatic head cancer. In case of pancreatic body or tail cancer, CHA and splenic artery (SA) were skeletonized, and the left-side plexus of SMA was dissected. If distant metastases were identified during the operation, pancreatectomy was abandoned (13).

Perioperative use of blood products and dose were determined by the attending surgeons, based on guidelines for the administration of blood products by the Japanese Ministry of Health and Welfare settled in 2005 (14), as well as on intraoperative blood loss, postoperative hemoglobin, serum albumin and prothrombin time. Postoperative patients were followed carefully as outpatients in our department. The tumor recurrence was defined as newly detected local or distant metastatic tumors by ultrasonography, computed tomography, or magnetic resonance image with or without an increase in serum carcinoembryonic antigen (CEA) or carbohydrate antigen 19-9 (CA19-9). In this study, local recurrences were identified as follows: i) perivascular (CHA or SMA) recurrence, ii) pancreaticojejunal anastomotic recurrence, iii) retroperitoneal recurrence and iv) regional lymph node recurrence. Other types of recurrence were defined as distant metastases. One hundred and seven patients $(71.8 \%)$ received adjuvant chemotherapy following pancreatic resection (either gemcitabine or $\mathrm{S}-1$, for six months), excluding the patients diagnosed as stage 0 , poor performance status (PS) or patients who refused therapy.

Identification of a novel score to predict local recurrence of pancreatic cancer. We calculated the distance from CHA or SMA to the edge of the tumor using preoperative $\mathrm{CT}$ imaging in all patients. The shortest distance was measured from CHA or SMA to the edge of tumor (CHA: Figure 1A and B, SMA: Figure 1C and 1D). The optimal cutoff level of the distance from CHA or SMA was determined by ROC analysis. The area under ROC (AUC) was measured and was compared to the presence of local recurrence of pancreatic cancer to evaluate the discrimination ability. After deciding the optimal cut-off value in each distance using ROC analysis, novel CHA or SMA scores were constructed to stratify the risk of local recurrence by combining the distance from CHA or SMA with the preoperative serum CA19-9 value. These are described in Table I. Next, to identify risk factors that can predict the local recurrence of pancreatic cancer, we investigated the relationship between clinicopathological variables and the occurrence of local recurrence in all patients with pancreatic cancer $(n=149)$, by using the logistic regression model. The following 17 variables were evaluated: age, gender, type of operation (PD or others), resection of portal vein, duration of operation, intraoperative blood loss, intraoperative RCC and FFP transfusion, differentiation of the tumor, TNM classification based on the Union for International Cancer Control (UICC) 8th edition (3), resection margin, lymphatic invasion (ly), venous invasion (v), distance from CHA or SMA, preoperative CA19-9 values, CHA score and SMA score. Finally, we investigated the relationship between clinicopathological variables and SMA score by univariate analysis. The variables consisted of the following 12 factors: age, gender, type of operation (PD or others), resection of portal vein, duration of operation, intraoperative blood loss, intraoperative RCC and FFP transfusion, differentiation of the tumor, TNM classification based on UICC 8th edition, resection margin, lymphatic invasion (ly) and venous invasion (v).

Effects of the novel scores on local recurrence-free survival and overall survival. We investigated the relationship between clinicopathological variables, local recurrence-free survival (LFS) and overall survival (OS) in patients with pancreatic cancer following elective pancreatic resection by univariate and multivariate analyses. Both the local recurrence group $(n=44)$ and recurrence-free group $(n=38)$ were used for this analysis. The following 14 variables were evaluated: age, gender, type of operation (PD or others), resection of the portal vein, duration of operation, intraoperative blood loss, intraoperative transfusion of RCC or FFP, differentiation of the tumor, TNM classification based on UICC 8th edition, resected margin, lymphatic invasion (ly), venous invasion (v), CHA score and SMA score.

Statistical analysis. Data were expressed as a median with an interquartile range (IQR) or ratio. Univariate analysis was performed using the Mann-Whitney's $U$-test, Kruskal-Wallis test, or Chi-square test, as appropriate. A logistic regression model with a backward elimination stepwise approach was used for the univariate 
(A)

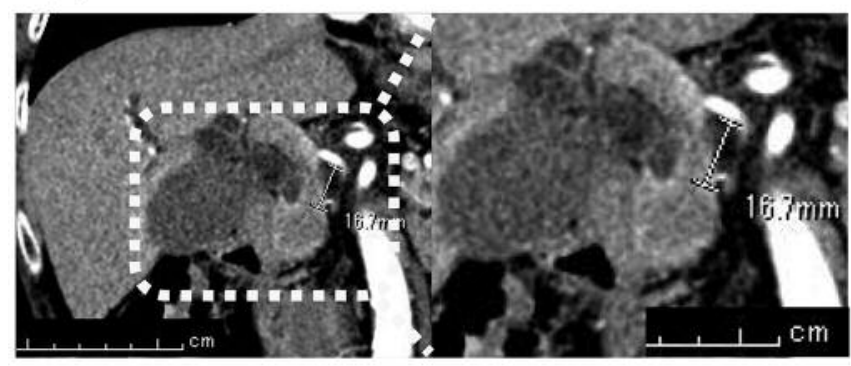

(C)

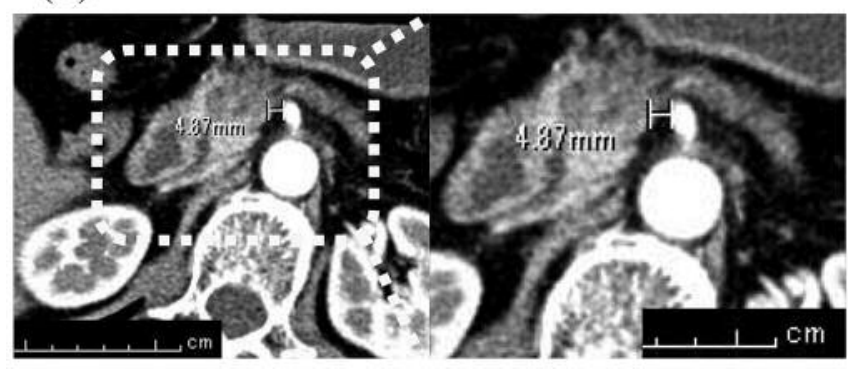

(B)

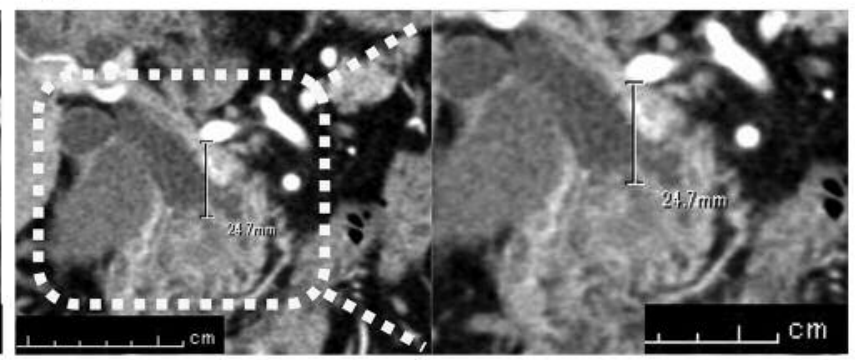

(D)

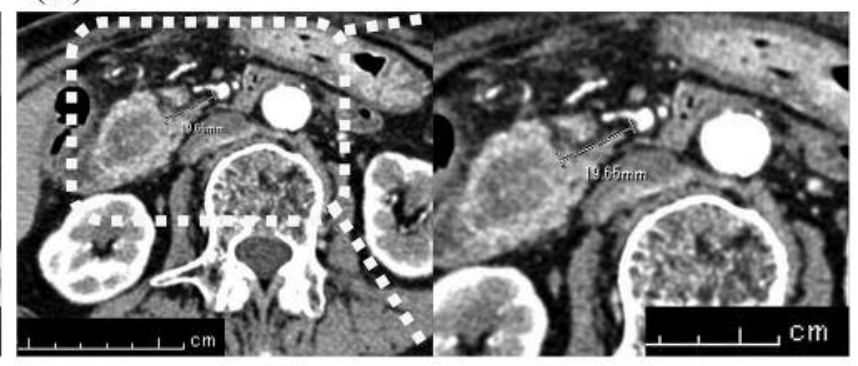

Figure 1. The shortest distance from CHA to the edge of the tumor (A: under $20.55 \mathrm{~mm}$, B: over $20.55 \mathrm{~mm}$ ). The shortest distance from SMA to the edge of the tumor (C: under $10.9 \mathrm{~mm}, \mathrm{D}$ : over $10.9 \mathrm{~mm}$ ). Scale bars: Centimeters are shown in each image.

and multivariate analyses of local recurrence. Both univariate and multivariate analyses of LFS or OS were performed using the Cox proportional regression model with a backward elimination stepwise approach. These analyses were conducted using IBM SPSS statistics version 24 (IBM Japan, Tokyo Japan). All $p$-values were considered statistically significant when the association probability was less than 0.05 .

\section{Results}

Patient characteristics. All patients' characteristics are outlined in Table I as a median, interquartile range, or ratio. The median DFS and OS of the entire study population were 1.03 years ( 0.86 to 1.21 years) and 2.48 years ( 1.60 to 3.35 years), respectively. In the current study, 5-year DFS and OS rate in patients with pancreatic cancer following pancreatic resection were $13.8 \%$ and $32.6 \%$, respectively. For the CHA or SMA distance from the edge of the tumor, based on the ROC analysis of the local recurrence, the optimal cut-off level of CHA distance was set as $20.55 \mathrm{~mm}$ with the AUC of 0.617 [95\% confidence interval $(\mathrm{CI})=0.519-0.715, p=0.025)$. For SMA distance, the cut-off value was $10.9 \mathrm{~mm}$ with the AUC of $0.670(95 \% \mathrm{CI}=0.578-0.761, p=0.001)$ (Figure 2A). The AUC value of SMA distance was greater than that of CHA distance. The relationship between the distance from CHA or SMA and the type of recurrence is shown in Figure 2B and C. SMA distance in the local recurrence group was significantly shorter compared to the two other groups $(p=0.004)$, while the CHA distance was comparable in each group.
Table I. The novel scores combining distance from main abdominal artery and pancreatic tumor with preoperative serum CA19-9 values.

\begin{tabular}{lcc}
\hline Index & & \\
\hline CHA score & Distance from & Preoperative serum \\
& CHA $(\mathrm{mm})$ & CA19-9 $\left(\mathrm{Uml}^{-1}\right)$ \\
0 & $\geq 20.55 \mathrm{~mm}$ & $\leq 200 \mathrm{Uml}^{-1}$ \\
1 & $<20.55 \mathrm{~mm}$ & $\leq 200 \mathrm{Uml}^{-1}$ \\
1 & $\geq 20.55 \mathrm{~mm}$ & $>200 \mathrm{Uml}^{-1}$ \\
2 & $<20.55 \mathrm{~mm}$ & $>200 \mathrm{Uml}^{-1}$ \\
SMA score & Distance from & Preoperative serum \\
& SMA $(\mathrm{mm})$ & CA19-9 $\left(\mathrm{Uml}^{-1}\right)$ \\
0 & $\geq 10.9 \mathrm{~mm}$ & $\leq 200 \mathrm{Uml}^{-1}$ \\
1 & $<10.9 \mathrm{~mm}$ & $\leq 200 \mathrm{Uml}^{-1}$ \\
1 & $\geq 10.9 \mathrm{~mm}$ & $>200 \mathrm{Uml}^{-1}$ \\
2 & $<10.9 \mathrm{~mm}$ & $>200 \mathrm{Uml}^{-1}$ \\
\hline
\end{tabular}

CHA: Common hepatic artery; SMA: superior mesenteric artery; CA19-9: carbohydrate antigen 19-9.

Univariate and multivariate analyses of clinicopathological variables in relation to the occurrence of local recurrence following pancreatic resection. Novel CHA or SMA scores using the optimal cut-off values were constructed, as described in Table II. Table III lists the relationship between the clinical variables and the occurrence of local recurrence following pancreatic resection using a logistic progression analysis. In the univariate analysis, factors that positively associated with the occurrence of local recurrence consisted of: i) lymphatic 
(A)

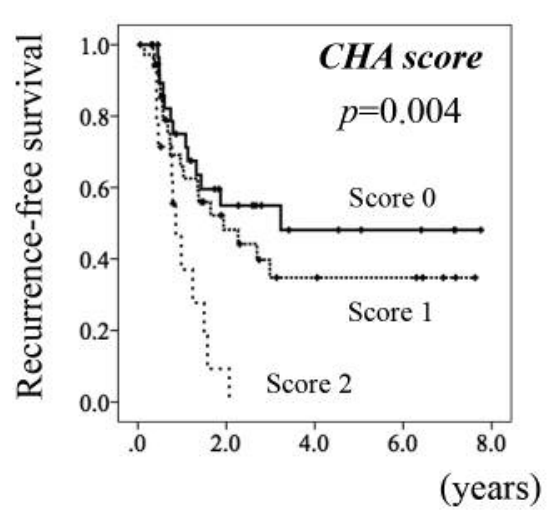

(C)

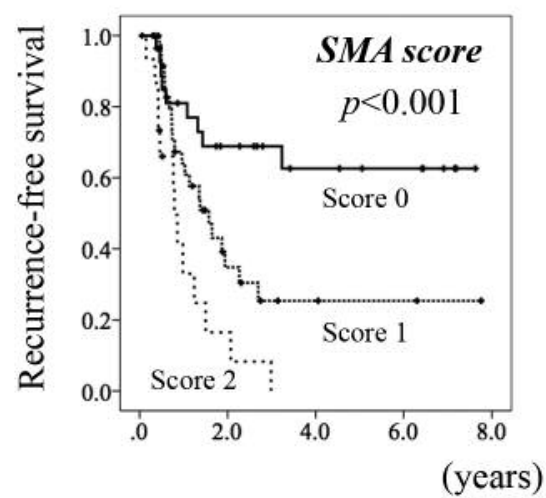

(B)

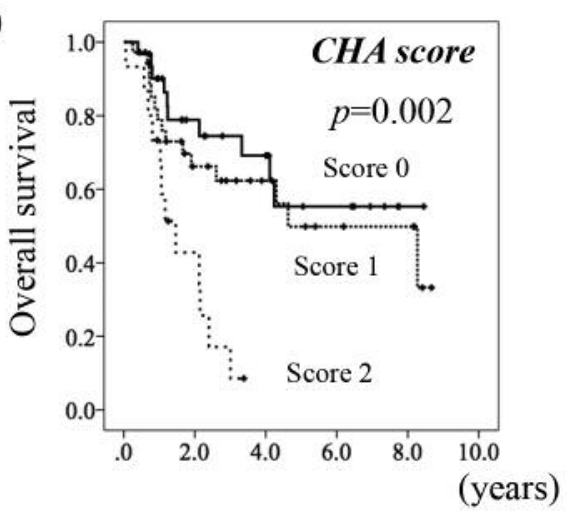

(D)

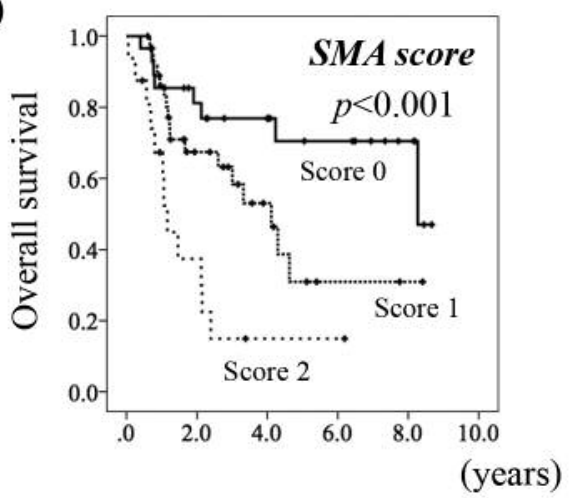

Figure 2. (A) ROC curve of distance from CHA or SMA in relation to the local recurrence after pancreatic resection. The optimal cut-off level for the distance from CHA was $20.55 \mathrm{~mm}$, with an AUC of 0.617 (95\% CI=0.519-0.715, $p=0.025)$. On the other hand, the distance from SMA was 10.9 $\mathrm{mm}$, with the AUC of 0.670 (95\% CI=0.578-0.761, $p=0.001)$. Relationship between distance from CHA $(B)$ or SMA $(C)$ and the type of recurrence.

invasion $(p=0.003)$, ii) distance from CHA $(p=0.030)$, iii $)$ distance from SMA $(p=0.017)$, iv) CHA score $(p=0.042)$ and v) SMA score $(p=0.004)$. In the multivariate analysis, lymphatic invasion $(p=0.002)$, preoperative elevated serum CA19-9 $\geq 200 \mathrm{Uml}^{-1}(p=0.007)$ and SMA score $(p=0.004)$ were independent predictors of local recurrence, while SMA distance alone was not an independent predictor of local recurrence. The hazard ratio of SMA score 2 was 29.28, which was greater than that of preoperative elevated serum CA19-9 (hazard ratio=13.32) using multivariate analysis. These results showed that a novel SMA score combining SMA distance and preoperative serum CA19-9 values was superior to SMA distance or preoperative serum CA19-9 values alone for predicting the occurrence of local recurrence.

Table IV lists the relationship between the clinicopathological variables and the SMA score. In the univariate analysis, factors that positively correlated with SMA score 2 consisted of duration of operation $(p=0.007)$, intraoperative RCC and FFP transfusion $(p=0.016)$.

Univariate and multivariate analyses of clinicopathological variables in relation to local recurrence-free survival (LFS), as well as to overall survival in both local recurrence and recurrence-free groups, following elective pancreatic resection. Table $\mathrm{V}$ lists the relationship between the clinical variables and LFS as well as OS in pancreatic cancer patients with pancreatic cancer after pancreatic resection. The samples were separated in a local recurrence group and a recurrence-free group in this analysis. In the univariate analysis, factors positively associated with local recurrence DFS were: i) resection of portal vein $(p=0.008)$, ii) advanced TNM classification based on UICC 8th edition $(p=0.008)$, iii) lymphatic invasion $(p<0.001)$, and iv) CHA score $(p=0.004)$ (Figure 3A) and SMA score $(p<0.001)$ (Figure $3 \mathrm{C}$ ). In the multivariate analysis, intraoperative blood loss $\geq 1,000 \mathrm{ml}(p=0.022)$, lymphatic invasion $(p=0.001)$ and SMA score $(p<0.001)$ were independent factors associated with local recurrence. Using a univariate analysis, reconstruction of portal vein $(p=0.011)$, differentiation of the tumor (modulate and poor) $(p=0.046)$, lymphatic invasion $(p=0.025), \mathrm{CHA}$ score $(p=0.002)$ (Figure 3B) and SMA score $(p<0.001)$ (Figure $3 \mathrm{D})$ were positively associated with $\mathrm{OS}$. In the multivariate analysis, intraoperative blood loss $\geq 1,000 \mathrm{ml}(p=0.045)$, intraoperative RCC or FFP transfusion $(p=0.026)$ and SMA score $(p<0.001)$ were independent factors of OS. 
Table II. Patient characteristics.

\begin{tabular}{|c|c|c|}
\hline Characteristic & $\begin{array}{l}\text { Median or } \\
\text { rate }\end{array}$ & IQR \\
\hline \multicolumn{3}{|l|}{ Age } \\
\hline years & 69.0 & $62-75$ \\
\hline \multicolumn{3}{|l|}{ Gender } \\
\hline Male/Female & $87 / 62$ & \\
\hline \multicolumn{3}{|l|}{ Disease-free survival } \\
\hline $\begin{array}{l}\text { Overall survival } \\
\text { years }\end{array}$ & $2.48 *$ & $1.60-3.35 * *$ \\
\hline \multicolumn{3}{|l|}{ Type of recurrence } \\
\hline $\begin{array}{l}\text { No recurrence/Loc } \\
\text { Distant Metastasis }\end{array}$ & $38 / 44 / 67$ & \\
\hline \multicolumn{3}{|l|}{ Type of operation } \\
\hline PD/non-PD & $92 / 57$ & \\
\hline \multicolumn{3}{|c|}{ Resection of portal vein } \\
\hline Present/Absent & $127 / 22$ & \\
\hline \multicolumn{3}{|l|}{ Duration of operation } \\
\hline \multicolumn{3}{|c|}{ Intraoperative blood loss } \\
\hline $\mathrm{ml}$ & 680.0 & $380-1,265$ \\
\hline \multicolumn{3}{|c|}{ Intraoperative transfusion of RCC or FFP } \\
\hline Present/Absent & $31 / 118$ & \\
\hline \multicolumn{3}{|c|}{ Differentiation of the tumor } \\
\hline Well/Others & $47 / 102$ & \\
\hline \multicolumn{3}{|c|}{ TNM classification based on UICC } \\
\hline I/II, III or IV & $46 / 103$ & \\
\hline \multicolumn{3}{|l|}{ Resection margin } \\
\hline R0/Others & $111 / 38$ & \\
\hline $\begin{array}{l}\text { Lymphatic invasion } \\
\text { ly0/Others }\end{array}$ & $52 / 97$ & \\
\hline \multicolumn{2}{|l|}{ Venous invasion (v) } & \\
\hline \multicolumn{3}{|c|}{ Preoperative serum CA19-9 } \\
\hline $\mathrm{Uml}^{-1}$ & 93.0 & $28-262$ \\
\hline $\begin{array}{l}\text { Distance from CHA } \\
\mathrm{mm}\end{array}$ & Distance from CHA & $13.1-34$ \\
\hline \multicolumn{3}{|l|}{ Distance from SMA } \\
\hline
\end{tabular}

*Median survival time. **95\%CI. IQR: Interquartile range; CA19-9: carbohydrate antigen 19-9; UICC: the Union for International Cancer Control.

\section{Discussion}

Our novel SMA score combining distance from SMA and preoperative serum CA19-9 values is simple and seems to be useful for predicting local recurrence of pancreatic cancer In the literature, independent predictors of local recurrence following pancreatic resection included male gender, perineural invasion, resected margin and adjuvant chemotherapy $(10,15)$. All factors, except for gender, were postoperative factors, and were, therefore, not known before resection. To our knowledge, the current study is the first report that identifies a predictor of local recurrence using preoperative variables in patients with pancreatic cancer.
To overcome the aggressive progression of pancreatic cancer, many surgeons have tried more aggressive and extended pancreatic resections, including extensive lymph node dissection, excision of the nerve plexus and combined vascular resection $(16,17)$. The approaches have been supported by some retrospective reports, which showed that negative margins are associated with longer survival in patients with pancreatic cancer $(18,19)$. Some other studies have shown that extended pancreatic resection fails to demonstrate an improved tumorrelated survival in all RCTs and tends to increase postoperative morbidity and mortality, as well as to worsen the quality of patients' life (QOL) (20-23). It appears that extended pancreatic resection in patients with pancreatic cancer is not a standard treatment worldwide. On the other hand, besides lymphadenectomy, dissection of the nerve plexus has been considered important in increasing the R0 resection and reducing the local recurrence $(17,24,25)$. Kimura et al., have reported that both extra-pancreatic nerve plexus and perineural invasion were poor prognostic factors in patients with pancreatic cancer (24). However, total circumferential dissection of the nerve plexus around the celiac axis or the SMA induces severe and intractable diarrhea, malnutrition and lower QOL following pancreatic resection $(23,24)$. To minimize these adverse effects of total circumferential nerve plexus dissection, right-sided 180degree dissection of the nerve plexus for pancreatic head cancer and left-sided for pancreatic body or tail cancer has been widely practiced in Japan (24).

One of the reasons why extended pancreatic resection has not improve prognosis and tends to increase morbidity, is that almost all patients with resectable pancreatic cancer are included in these trials. Many patients with low risk of local recurrence do not undergo extended lymph nodes and nerve plexus dissection. To minimize the adverse effects and maximize the oncological effects using extended pancreatic resection, a preoperatively risk stratification of local recurrence in patients with pancreatic cancer, using preoperative variables, is important to determine the degree of invasiveness of pancreatic resection preoperatively. To predict the time to recurrence of pancreatic cancer is also important for postoperative management and treatment. Groot et al. has already reported the relationship between time to recurrence and location of recurrence (10), of which the shortest time to recurrence after pancreatic resection was liver (median; 6.9 months) and longest was local recurrence (median $=9.5$ months). Our novel SMA score was not positively associated with the time to recurrence (data was not shown).

Recently, National Comprehensive Cancer Network (NCCN) provided clinical guidelines for the classification of pancreatic cancer into i) resectable, ii) borderline resectable (BRPC) and iii) unresectable pancreatic cancer (26). BRPC with arterial involvement (BR-A) is associated with poor prognosis, as compared to BRPC with portal or superior mesenteric vein involvement (BR-PV) $(27,28)$. Resection of BRPC without any 
Table III. Univariate and multivariate analyses of clinicopathological variables in relation to local recurrence including in patients with pancreatic cancer.

\begin{tabular}{|c|c|c|c|c|}
\hline \multirow[b]{2}{*}{ Factor } & \multicolumn{2}{|c|}{ Univariate } & \multicolumn{2}{|c|}{ Multivariate } \\
\hline & Hazard ratio $(95 \% \mathrm{CI})$ & $p$-Value & Hazard ratio $(95 \% \mathrm{CI})$ & $p$-Value \\
\hline \multicolumn{5}{|l|}{ Age } \\
\hline years & $1.026(0.989-1.066)$ & 0.173 & $1.040(0.911-1.091)$ & 0.111 \\
\hline \multicolumn{5}{|l|}{ Gender } \\
\hline Male & 1 (reference) & 0.401 & 1 (reference) & 0.082 \\
\hline Female & $0.733(0.355-1.514)$ & & $0.454(0.187-1.104)$ & \\
\hline \multicolumn{5}{|l|}{ Type of operation } \\
\hline PD & 1 (reference) & 0.297 & & NS \\
\hline Others & $0.673(0.320-1.416)$ & & & \\
\hline \multicolumn{5}{|c|}{ Resection of portal vein } \\
\hline Absent & 1 (reference) & 0.448 & & NS \\
\hline Present & $1.444(0.558-3.737)$ & & & \\
\hline \multicolumn{5}{|c|}{ Duration of operation } \\
\hline $\min$ & $1.002(1.000-1.005)$ & 0.085 & & NS \\
\hline \multicolumn{5}{|c|}{ Intraoperative Blood loss } \\
\hline $\mathrm{ml}$ & $1.000(1.000-1.001)$ & 0.212 & & NS \\
\hline \multicolumn{5}{|c|}{ Intraoperative transfusion of RCC or FFP } \\
\hline Absent & 1 (reference) & 0.211 & & NS \\
\hline Present & $1.697(0.741-3.888)$ & & & \\
\hline \multicolumn{5}{|c|}{ Differentiation of the tumor } \\
\hline Well & 1 (reference) & 0.665 & & NS \\
\hline Others & $1.180(0.558-2.496)$ & & & \\
\hline \multicolumn{5}{|c|}{ TNM classification based on UICC classification } \\
\hline Stage I & 1 (reference) & 0.820 & 1 (reference) & 0.137 \\
\hline Stage II, III or IV & $1.093(0.507-2.355)$ & & $2.165(0.782-5.998)$ & \\
\hline \multicolumn{5}{|l|}{ Resected margin } \\
\hline R0 & 1 (reference) & 2.519 & 1 (reference) & 0.071 \\
\hline $\mathrm{R} 1$ or $\mathrm{R} 2$ & $2.519(1.163-5.454)$ & & $2.375(0.930-6.067)$ & \\
\hline \multicolumn{5}{|c|}{ Lymphatic invasion (ly) } \\
\hline Ly 0 & 1 (reference) & 0.003 & 1 (reference) & 0.002 \\
\hline Ly 1,2 and 3 & $3.964(1.619-9.707)$ & & $5.386(1.889-15.356)$ & \\
\hline \multicolumn{5}{|l|}{ Venous invasion $(\mathrm{v})$} \\
\hline v0 & 1 (reference) & 0.178 & & NS \\
\hline $\mathrm{v} 1,2$ and 3 & $1.782(0.769-4.131)$ & & & \\
\hline \multicolumn{5}{|l|}{ Distance from CHA } \\
\hline $\mathrm{mm}$ & $0.974(0.951-0.997)$ & 0.030 & & NS \\
\hline \multicolumn{5}{|l|}{ Distance from SMA } \\
\hline $\mathrm{mm}$ & $0.952(0.915-0.991)$ & 0.017 & & NS \\
\hline \multicolumn{5}{|c|}{ Preoperative serum CA19-9 } \\
\hline$<200 \mathrm{Uml}^{-1}$ & 1 (reference) & 0.484 & 1 (reference) & 0.007 \\
\hline$\geq 200 \mathrm{Uml}^{-1}$ & $1.304(0.621-2.737)$ & & $13.32(2.207-87.59)$ & \\
\hline \multicolumn{5}{|l|}{ CHA score } \\
\hline 0 & 1 (reference) & 0.042 & 1 (reference) & 0.089 \\
\hline 1 & $1.131(0.501-2.554)$ & & $0.998(0.355-2.808)$ & \\
\hline 2 & $3.441(1.230-9.626)$ & & $6.122(0.883-42.436)$ & \\
\hline \multicolumn{5}{|l|}{ SMA score } \\
\hline 0 & 1 (reference) & 0.004 & 1 (reference) & 0.004 \\
\hline 1 & $2.109(0.880-5.055)$ & & $3.369(1.165-9.742)$ & \\
\hline 2 & $6.356(2.131-18.95)$ & & $29.48(3.90-222.9)$ & \\
\hline
\end{tabular}

PD: Pancreaticoduodenectomy; RCC: red blood cell concentrate; FFP: fresh frozen plasma; CHA: common hepatic artery; SMA: superior mesenteric artery; UICC: Union for International Cancer Control; CA19-9: carbohydrate antigen 19-9.

neoadjuvant therapy is at high risk for margin-positive resection and postoperative local recurrence (29). Other reports agree on the effectiveness of neoadjuvant chemoradiotherapy for BRPC or stage III pancreatic cancer $(30,31)$. Hackert et al. has also reported that the resection rate of patients with locally advanced pancreatic cancer following FOLFIRINOX was $61 \%$, compared to $41 \%$ following gemcitabine with radiotherapy (32). Therefore, neoadjuvant therapy for patients with BRPC may 
(A)

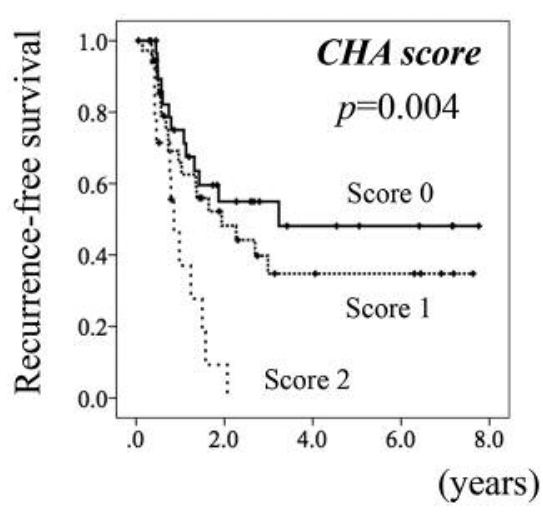

(C)

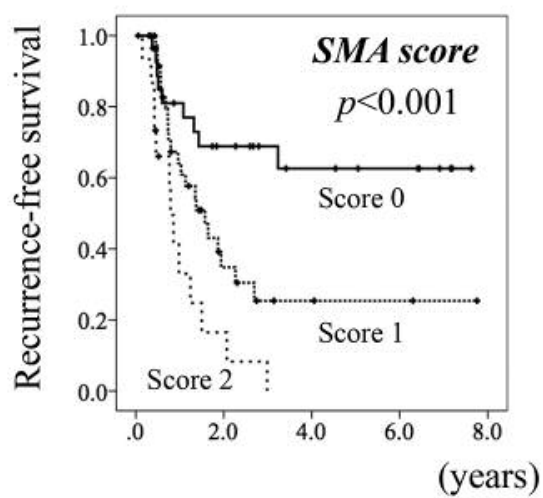

(B)

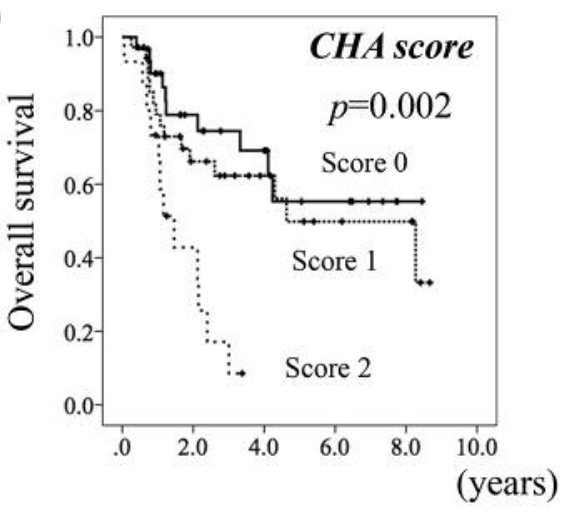

(D)

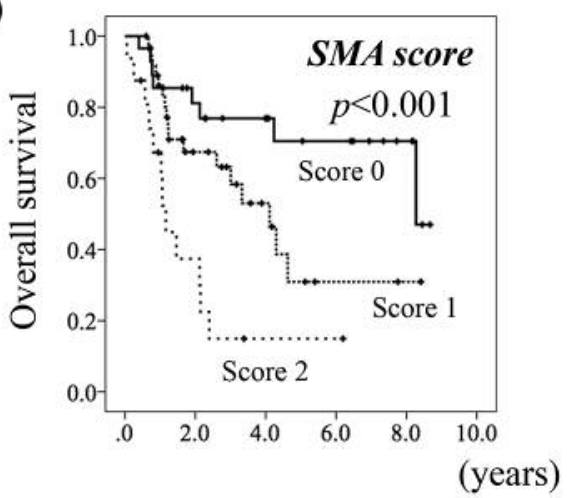

Figure 3. Kaplan-Meier curves of local recurrence-free survival ( $A$ and $C$, respectively) and overall survival ( $B$ and $D$, respectively) in relation to CHA score and SMA score, respectively. Patients in this analysis were classified as recurrence-free and local recurrence group. Both CHA and SMA scores were negatively associated with local recurrence-free survival $(p=0.004, p<0.001)$ and overall survival $(p=0.002, p<0.001)$, respectively.

Table IV. Univariate analysis of patients' characteristics in relation to SMA score in patients with pancreatic cancer.

\begin{tabular}{|c|c|c|c|c|}
\hline \multirow[t]{2}{*}{ Factor } & \multicolumn{3}{|c|}{ SMA score $(n=149)$} & \multirow[t]{2}{*}{$p$-Value } \\
\hline & $0(\mathrm{~N}=53)$ & $1(\mathrm{~N}=73)$ & $2(\mathrm{~N}=23)$ & \\
\hline Age (years) & $69(61.5-76.0)^{*}$ & $68.0(61.5-74.0)^{*}$ & $72.0(62.0-77.0)^{*}$ & 0.313 \\
\hline Gender (male/female) & $30 / 23$ & $45 / 28$ & $12 / 11$ & 0.686 \\
\hline Type of operation (PD/non-PD) & $27 / 26$ & $47 / 26$ & $18 / 5$ & 0.064 \\
\hline Reconstruction of portal vein (present/absent) & $49 / 4$ & $61 / 12$ & $17 / 6$ & 0.095 \\
\hline Duration of operation (min) & $490.0(399.5-547.0)^{*}$ & $508.0(425.0-598.5)^{*}$ & $540.0(489 .-0-641.0)^{*}$ & 0.007 \\
\hline Intraoperative blood loss (ml) & $553.0(300.0-1,170.0)^{*}$ & $690.0(390.0-1,215.0)^{*}$ & $1,040.0(600.0-1,810.0)^{*}$ & 0.067 \\
\hline Intraoperative transfusion of RCC or FFP (present/absent) & $40 / 13$ & $64 / 9$ & $14 / 9$ & 0.016 \\
\hline Differentiation of the tumor (well/others) & $23 / 30$ & $19 / 54$ & $5 / 18$ & 0.064 \\
\hline TNM classification based on UICC (I/II, III or IV) & $21 / 32$ & $22 / 51$ & $3 / 20$ & 0.069 \\
\hline Resected margin (R0/R1 or R2) & $42 / 11$ & $55 / 18$ & $14 / 9$ & 0.234 \\
\hline Lymphatic invasion (ly) (ly0/1y 1,2 or 3$)$ & $22 / 31$ & $25 / 48$ & $5 / 18$ & 0.248 \\
\hline Venous invasion $(\mathrm{v})(\mathrm{v} 0 / \mathrm{v} 1,2$ or 3$)$ & $18 / 35$ & $21 / 52$ & $3 / 20$ & 0.175 \\
\hline
\end{tabular}

PD: Pancreaticoduodenectomy; RCC: red blood cell concentrate; FFP: fresh frozen plasma; UICC: Union for International Cancer Control; *Median (IQR: interquartile range).

become the standard therapeutic approach. In this regard, our study showed that neoadjuvant chemotherapy or radiochemotherapy in patients with pancreatic cancer should be supplemented with SMA score 2 prior to extended pancreatic resection to reduce the local recurrence, regardless of the type of pancreatic cancer classified using the NCCN guidelines (26).

There were several limitations to the current study. The study was retrospective, included a small sample size, and was 
Table V. Univariate and multivariate analyses of clinicopathological variables in relation to LFS and OS in patients with pancreatic cancer (recurrence-free group and local recurrence group).

\begin{tabular}{|c|c|c|c|c|c|c|c|c|c|}
\hline \multirow[b]{3}{*}{ Factor } & \multirow[b]{3}{*}{$\mathrm{N}$} & \multicolumn{4}{|c|}{ LFS } & \multicolumn{4}{|c|}{ OS } \\
\hline & & \multicolumn{2}{|c|}{ Univariate } & \multicolumn{2}{|c|}{ Multivariate } & \multicolumn{2}{|c|}{ Univariate } & \multicolumn{2}{|c|}{ Multivariate } \\
\hline & & $\begin{array}{l}\text { Hazard ratio } \\
(95 \% \mathrm{CI})\end{array}$ & $p$-Value & $\begin{array}{c}\text { Hazard ratio } \\
(95 \% \mathrm{CI})\end{array}$ & $p$-Value & $\begin{array}{c}\text { Hazard ratio } \\
(95 \% \mathrm{CI})\end{array}$ & $p$-Value & $\begin{array}{c}\text { Hazard ratio } \\
(95 \% \mathrm{CI})\end{array}$ & $p$-Value \\
\hline \multicolumn{10}{|l|}{ Age } \\
\hline$<60$ years & 16 & 1 (reference) & 0.454 & $\begin{array}{l}\text { Did not remain } \\
\text { in this model }\end{array}$ & & 1 (reference) & 0323 & $\begin{array}{l}\text { Did not remain } \\
\text { in this model }\end{array}$ & \\
\hline$\geq 60$ years & 67 & $0.746(0.346-1.607)$ & & & & $0.672(0.306-1.477)$ & & & \\
\hline \multicolumn{10}{|l|}{ Gender } \\
\hline Male & 46 & 1 (reference) & 0.117 & $\begin{array}{l}\text { Did not remain } \\
\text { in this model }\end{array}$ & & 1 (reference) & 0.055 & 1 (reference) & 0.057 \\
\hline Female & 36 & $0.611(0.330-1.132)$ & & & & $0.500(0.246-1.016)$ & & $0.495(0.240-1.021)$ & \\
\hline \multicolumn{10}{|l|}{ Type of operation } \\
\hline $\mathrm{PD}$ & 49 & 1 (reference) & 0.067 & $\begin{array}{l}\text { Did not remain } \\
\text { in this model }\end{array}$ & & 1 (reference) & 0.197 & $\begin{array}{l}\text { Did not remain } \\
\text { in this model }\end{array}$ & \\
\hline Others & 33 & $0.552(0.292-1.043)$ & & & & $0.641(0.326-1.260)$ & & & \\
\hline \multicolumn{10}{|l|}{$\begin{array}{l}\text { Reconstruction } \\
\text { of portal vein }\end{array}$} \\
\hline Absent & 71 & 1 (reference) & 0.008 & $\begin{array}{l}\text { Did not remain } \\
\text { in this model }\end{array}$ & & 1 (reference) & 0.011 & $\begin{array}{l}\text { Did not remain } \\
\text { in this model }\end{array}$ & \\
\hline Present & 11 & $2.933(1.322-6.508)$ & & & & $3.080(1.290-7.355)$ & & & \\
\hline \multicolumn{10}{|c|}{ Duration of operation } \\
\hline$<500 \mathrm{~min}$ & 40 & 1 (reference) & 0.165 & $\begin{array}{l}\text { Did not remain } \\
\text { in this model }\end{array}$ & & 1 (reference) & 0.516 & $\begin{array}{l}\text { Did not remain } \\
\text { in this model }\end{array}$ & \\
\hline $\begin{array}{l}\geq 500 \text { min } \\
\text { Intraoperative }\end{array}$ & 42 & $1.532(0.839-2.796)$ & & & & $1.240(0.647-2.377)$ & & & \\
\hline \multicolumn{10}{|l|}{ blood loss } \\
\hline$<1,000 \mathrm{ml}$ & 54 & 1 (reference) & 0.503 & 1 (reference) & 0.022 & 1 (reference) & 0.495 & 1 (reference) & 0.045 \\
\hline$\geq 1,000 \mathrm{ml}$ & 28 & $1.228(0.673-2.242)$ & & $2.304(1.125-4.719)$ & & $1.257(0.652-2.426)$ & & $2.189(1.106-4.716)$ & \\
\hline \multicolumn{10}{|l|}{$\begin{array}{l}\text { Intraoperative } \\
\text { transfusion of } \\
\text { RCC or FFP }\end{array}$} \\
\hline Absent & 63 & 1 (reference) & 0.407 & 1 (reference) & 0.100 & 1 (reference) & 0.174 & 1 (reference) & 0.026 \\
\hline Present & 19 & $1.326(0.681-2.580)$ & & $1.879(0.887-3.980)$ & & $1.627(0.807-3.282)$ & & $2.465(1.116-5.443)$ & \\
\hline \multicolumn{10}{|l|}{$\begin{array}{l}\text { Differentiation } \\
\text { of the tumor }\end{array}$} \\
\hline Well & 34 & 1 (reference) & 0.059 & $\begin{array}{l}\text { Did not remain } \\
\text { in this model }\end{array}$ & & 1 (reference) & 0.046 & 1 (reference) & 0.097 \\
\hline Others & 48 & $1.838(0.976-3.463)$ & & & & $2.081(1.013-4.279)$ & & $1.926(0.888-4.178)$ & \\
\hline \multicolumn{10}{|l|}{$\begin{array}{l}\text { TNM classification } \\
\text { based on UICC } \\
\text { classification }\end{array}$} \\
\hline Stage I & 31 & 1 (reference) & 0.028 & $\begin{array}{l}\text { Did not remain } \\
\text { in this model }\end{array}$ & & 1 (reference) & 0.055 & $\begin{array}{l}\text { Did not remain } \\
\text { in this model }\end{array}$ & \\
\hline Stage II, III or IV & 51 & $2.078(1.083-3.987)$ & & & & $2.039(0.984-4.226)$ & & & \\
\hline \multicolumn{10}{|l|}{ Resection margin } \\
\hline R0 & 58 & 1 (reference) & 0.056 & $\begin{array}{l}\text { Did not remain } \\
\text { in this model }\end{array}$ & & 1 (reference) & 0.081 & $\begin{array}{l}\text { Did not remain } \\
\text { in this model }\end{array}$ & \\
\hline $\mathrm{R} 1$ or $\mathrm{R} 2$ & 24 & $1.813(0.984-3.342)$ & & & & $1.817(0.929-3.553)$ & & & \\
\hline \multicolumn{10}{|l|}{$\begin{array}{l}\text { Lymphatic } \\
\text { invasion (ly) }\end{array}$} \\
\hline ly 0 & 30 & 1 (reference) & $<0.001$ & 1 (reference) & 0.001 & 1 (reference) & 0.025 & $\begin{array}{l}\text { Did not remain } \\
\text { in this model }\end{array}$ & \\
\hline ly 1,2 and 3 & 52 & $4.741(2.097-10.718)$ & & $4.645(1.956-11.033)$ & & $2.385(1.118-5.088)$ & & & \\
\hline \multicolumn{10}{|l|}{ Venous invasion (v) } \\
\hline v0 & 25 & 1 (reference) & 0.065 & $\begin{array}{l}\text { Did not remain } \\
\text { in this model }\end{array}$ & & 1 (reference) & 0.606 & $\begin{array}{l}\text { Did not remain } \\
\text { in this model }\end{array}$ & \\
\hline $\mathrm{v} 1,2$ and 3 & 57 & $1.994(0.957-4.155)$ & & & & $1.211(0.585-2.506)$ & & & \\
\hline
\end{tabular}


Table V. Continued

\begin{tabular}{|c|c|c|c|c|c|c|c|c|c|}
\hline \multicolumn{10}{|l|}{ CHA score } \\
\hline 0 & 31 & 1 (reference) & 0.004 & $\begin{array}{l}\text { Did not remain } \\
\text { in this model }\end{array}$ & & 1 (reference) & 0.002 & $\begin{array}{l}\text { Did not remain } \\
\text { in this model }\end{array}$ & \\
\hline 1 & 36 & $1.400(0.691-2.836)$ & & & & $1.352(0.606-3.019)$ & & & \\
\hline 2 & 15 & $3.710(1.652-8.332)$ & & & & $4.499(1.890-10.706)$ & & & \\
\hline \multicolumn{10}{|l|}{ SMA score } \\
\hline 0 & 29 & 1 (reference) & $<0.001$ & 1 (reference) & $<0.001$ & 1 (reference) & $<0.001$ & 1 (reference) & $<0.001$ \\
\hline 1 & 37 & $2.645(1.203-5.819)$ & & $3.666(1.599-8.404)$ & & $2.194(0.935-5.147)$ & & $2.432(0.973-6.081)$ & \\
\hline 2 & 16 & $6.172(2.572-14.811)$ & & $.903(2.286-15.240)$ & & $5.967(2.367-15.048)$ & & $7.122(2.513-20.187)$ & \\
\hline
\end{tabular}

The patients of this analysis included in recurrence-free group and local recurrence group. A backward elimination with a threshold of $p=0.05$ was used to select variables for the final model of the multivariate analysis. PD: Pancreaticoduodenectomy; RCC: red blood cell concentrate; FFP: fresh frozen plasma; CHA: common hepatic artery; SMA: superior mesenteric artery; UICC: Union for International Cancer Control; CA19-9: carbohydrate antigen 19-9; LFS: local recurrence-free survival; OS: overall survival.

a single-institutional design. To prove our hypothesis it seems important to perform a prospective study using the SMA score, in order to determine the invasiveness of pancreatic resection in patients with pancreatic cancer. Risk stratification using the SMA score can be performed easily before surgery, using CT imaging and tumor marker, which are considered as standards in preoperative management. This SMA score could be helpful in clinical decisions, including the administration of neoadjuvant chemotherapy and surgical treatment. The novel SMA score combining the distance between SMA and tumor with the preoperative serum CA19-9 value may be an independent predictor of local recurrence and prognosis in patients with pancreatic cancer and allow the preoperative determination of the extent of pancreatic resection.

\section{Conflicts of Interest}

All authors declare no conflicts of interests.

\section{Authors' Contributions}

F.S. and Y.F. designed the study, collected and analyzed the data as well as wrote the manuscript. R.H., K.H., T.S. and H.S. collected the data and helped with the analysis. Y.K. reviewed the manuscript.

\section{Ethics Approval}

This study was approved by the Ethics Committee of the Jikei University School of Medicine (21-121).

\section{References}

1 Siegel RL, Miller KD and Jemal A: Cancer statistics, 2018. CA Cancer J Clin 68: 7-30, 2018. PMID: 29313949. DOI: 10.3322/ caac. 21442

2 Rahib L, Smith BD, Aizenberg R, Rosenzweig AB, Fleshman JM and Matrisian LM: Projecting cancer incidence and deaths to 2030: the unexpected burden of thyroid, liver, and pancreas cancers in the United States. Cancer Res 74: 2913-2921, 2014. PMID: 24840647. DOI: 10.1158/0008-5472.CAN-14-0155
3 Bilimoria KY, Bentrem DJ, Ko CY, Stewart AK, Winchester DP and Talamonti MS: National failure to operate on early stage pancreatic cancer. Ann Surg 246: 173-180, 2007. PMID: 17667493. DOI: $10.1097 /$ SLA.0b013e3180691579

4 Kang MJ, Jang JY, Lee SE, Lim CS, Lee KU and Kim SW: Comparison of the long-term outcomes of uncinate process cancer and non-uncinate process pancreas head cancer: poor prognosis accompanied by early locoregional recurrence. Langenbecks Arch Surg 395: 697-706, 2010. PMID: 20652784. DOI: $10.1007 / \mathrm{s} 00423-010-0593-6$

5 Ferrone CR, Brennan MF, Gonen M, Coit DG, Fong Y, Chung S, Tang L, Klimstra D and Allen PJ: Pancreatic adenocarcinoma: the actual 5-year survivors. J Gastrointest Surg 12: 701-706, 2008. PMID: 18027062. DOI: 10.1007/s11605-007-0384-8

6 Ferrone CR, Pieretti-Vanmarcke R, Bloom JP, Zheng H, Szymonifka J, Wargo JA, Thayer SP, Lauwers GY, Deshpande V, Mino-Kenudson M, Fernandez-del Castillo C, Lillemoe KD and Warshaw AL: Pancreatic ductal adenocarcinoma: long-term survival does not equal cure. Surgery 152: S43-49, 2012. PMID: 22763261. DOI: 10.1016/j.surg.2012.05.020

7 He J, Ahuja N, Makary MA, Cameron JL, Eckhauser FE, Choti MA, Hruban RH, Pawlik TM and Wolfgang CL: 2564 resected periampullary adenocarcinomas at a single institution: trends over three decades. HPB (Oxford) 16: 83-90, 2014. PMID: 23472829. DOI: $10.1111 / \mathrm{hpb} .12078$

8 Howard TJ, Krug JE, Yu J, Zyromski NJ, Schmidt CM, Jacobson LE, Madura JA, Wiebke EA and Lillemoe KD: A margin-negative R0 resection accomplished with minimal postoperative complications is the surgeon's contribution to long-term survival in pancreatic cancer. J Gastrointest Surg 10: 1338-1345; discussion 1345-1336, 2006. PMID: 17175452. DOI: 10.1016/ j.gassur.2006.09.008

9 Moon HJ, An JY, Heo JS, Choi SH, Joh JW and Kim YI: Predicting survival after surgical resection for pancreatic ductal adenocarcinoma. Pancreas 32: 37-43, 2006. PMID: 16340742.

10 Groot VP, Rezaee N, Wu W, Cameron JL, Fishman EK, Hruban RH, Weiss MJ, Zheng L, Wolfgang CL and He J: Patterns, timing, and predictors of recurrence following pancreatectomy for pancreatic ductal adenocarcinoma. Ann Surg 267: 936-945, 2018. PMID: 28338509. DOI: $10.1097 /$ SLA.0000000000002234

11 Groot VP, van Santvoort HC, Rombouts SJ, Hagendoorn J, Borel Rinkes IH, van Vulpen M, Herman JM, Wolfgang CL, Besselink MG and Molenaar IQ: Systematic review on the treatment of isolated local recurrence of pancreatic cancer after surgery; re- 
resection, chemoradiotherapy and SBRT. HPB (Oxford) 19: 8392, 2017. PMID: 28065427. DOI: 10.1016/j.hpb.2016.11.001

12 Iacobuzio-Donahue CA, Fu B, Yachida S, Luo M, Abe H, Henderson CM, Vilardell F, Wang Z, Keller JW, Banerjee P, Herman JM, Cameron JL, Yeo CJ, Halushka MK, Eshleman JR, Raben M, Klein AP, Hruban RH, Hidalgo M and Laheru D: DPC4 gene status of the primary carcinoma correlates with patterns of failure in patients with pancreatic cancer. J Clin Oncol 27: 18061813, 2009. PMID: 19273710. DOI: $10.1200 /$ JCO.2008.17.7188

13 Yamaguchi K, Okusaka T, Shimizu K, Furuse J, Ito Y, Hanada $\mathrm{K}$, Shimosegawa T, Okazaki K and Committee for revision of clinical guidelines for pancreatic cancer of the Japan pancreas: Clinical practice guidelines for pancreatic cancer 2016 from the Japan Pancreas Society: A synopsis. Pancreas 46: 595-604, 2017. PMID: 28426492. DOI: 10.1097/MPA.0000000000000816

14 Japanese Bureau of Medical Safety MoHaW: Guidelines for administrating blood preparations. Medical and Pharmaceutical Notification 10: No.715, 1999.

15 Kim S IM, Arena J, Nahm C, Pavlakis N, Clarke S, Gill A, Samra JS and Mittal A: Patterns and determinants of recurrence for pancreatic ductal adenocarcinoma after resection. JOP J Pancreas (Online) 30: 458-464, 2017.

16 Manabe T, Ohshio G, Baba N, Miyashita T, Asano N, Tamura K, Yamaki K, Nonaka A and Tobe T: Radical pancreatectomy for ductal cell carcinoma of the head of the pancreas. Cancer 64 : 1132-1137, 1989. PMID: 2547508.

17 Nakao A, Takeda S, Sakai M, Kaneko T, Inoue S, Sugimoto H and Kanazumi N: Extended radical resection versus standard resection for pancreatic cancer: the rationale for extended radical resection. Pancreas 28: 289-292, 2004. PMID: 15084973.

18 Iacono C, Accordini S, Bortolasi L, Facci E, Zamboni G, Montresor E, Marinello PD and Serio G: Results of pancreaticoduodenectomy for pancreatic cancer: Extended versus standard procedure. World J Surg 26: 1309-1314, 2002. PMID: 12297922. DOI: 10.1007/s00268-002-5976-6

19 Ishikawa O, Ohhigashi H, Sasaki Y, Kabuto T, Fukuda I, Furukawa $\mathrm{H}$, Imaoka S and Iwanaga T: Practical usefulness of lymphatic and connective tissue clearance for the carcinoma of the pancreas head. Ann Surg 208: 215-220, 1988. PMID: 2840866.

20 Jang JY, Kang MJ, Heo JS, Choi SH, Choi DW, Park SJ, Han SS, Yoon DS, Yu HC, Kang KJ, Kim SG and Kim SW: A prospective randomized controlled study comparing outcomes of standard resection and extended resection, including dissection of the nerve plexus and various lymph nodes, in patients with pancreatic head cancer. Ann Surg 259: 656-664, 2014. PMID: 24368638. DOI: $10.1097 /$ SLA.0000000000000384

21 Michalski CW, Kleeff J, Wente MN, Diener MK, Buchler MW and Friess H: Systematic review and meta-analysis of standard and extended lymphadenectomy in pancreaticoduodenectomy for pancreatic cancer. Br J Surg 94: 265-273, 2007. PMID: 17318801. DOI: $10.1002 /$ bjs. 5716

22 Nimura Y, Nagino M, Takao S, Takada T, Miyazaki K, Kawarada Y, Miyagawa S, Yamaguchi A, Ishiyama S, Takeda Y, Sakoda K, Kinoshita T, Yasui K, Shimada H and Katoh H: Standard versus extended lymphadenectomy in radical pancreatoduodenectomy for ductal adenocarcinoma of the head of the pancreas: long-term results of a Japanese multicenter randomized controlled trial. J Hepatobiliary Pancreat Sci 19: 230-241, 2012. PMID: 22038501. DOI: $10.1007 / \mathrm{s} 00534-011-0466-6$

23 Yeo CJ, Cameron JL, Lillemoe KD, Sohn TA, Campbell KA, Sauter PK, Coleman J, Abrams RA and Hruban RH:
Pancreaticoduodenectomy with or without distal gastrectomy and extended retroperitoneal lymphadenectomy for periampullary adenocarcinoma, part 2: Randomized controlled trial evaluating survival, morbidity, and mortality. Ann Surg 236: 355-366; discussion 366-358, 2002. PMID: 12192322. DOI: 10.1097/ 01.SLA.0000027272.08464.0B

24 Kimura W: Strategies for the treatment of invasive ductal carcinoma of the pancreas and how to achieve zero mortality for pancreaticoduodenectomy. J Hepatobiliary Pancreat Surg 15: 270277, 2008. PMID: 18535764. DOI: 10.1007/s00534-007-1305-7

25 Pawlik TM, Abdalla EK, Barnett CC, Ahmad SA, Cleary KR, Vauthey JN, Lee JE, Evans DB and Pisters PW: Feasibility of a randomized trial of extended lymphadenectomy for pancreatic cancer. Arch Surg 140: 584-589; discussion 589-591, 2005. PMID: 15967906. DOI: $10.1001 /$ archsurg.140.6.584

26 National Comprehensive Cancer Network: Practice guideline in oncology for pancreatic adnocarcinoma version 2, 2015.

27 Kato K, Mikami K, Akama F, Yamada K, Maehara M, Kimoto K, Kimoto K, Sato R, Takahashi Y, Fukushima R, Ichimura A and Matsumoto H: Clinical features of suicide attempts in adults with autism spectrum disorders. Gen Hosp Psychiatry 35: 50-53, 2013. PMID: 23141028. DOI: 10.1016/j.genhosppsych. 2012.09.006

28 Murakami Y, Satoi S, Sho M, Motoi F, Matsumoto I, Kawai M, Honda G, Uemura K, Yanagimoto H, Shinzeki M, Kurata M, Kinoshita S, Yamaue H and Unno M: National Comprehensive Cancer Network Resectability Status for Pancreatic Carcinoma Predicts Overall Survival. World J Surg 39: 2306-2314, 2015. PMID: 26013206. DOI: 10.1007/s00268-015-3096-3

29 Bockhorn M, Uzunoglu FG, Adham M, Imrie C, Milicevic M, Sandberg AA, Asbun HJ, Bassi C, Buchler M, Charnley RM, Conlon K, Cruz LF, Dervenis C, Fingerhutt A, Friess H, Gouma DJ, Hartwig W, Lillemoe KD, Montorsi M, Neoptolemos JP, Shrikhande SV, Takaori K, Traverso W, Vashist YK, Vollmer C, Yeo CJ, Izbicki JR and International Study Group of Pancreatic S: Borderline resectable pancreatic cancer: a consensus statement by the International Study Group of Pancreatic Surgery (ISGPS). Surgery 155: 977-988, 2014. PMID: 24856119. DOI: 10.1016/j.surg.2014.02.001

30 Shubert CR, Bergquist JR, Groeschl RT, Habermann EB, Wilson PM, Truty MJ, Smoot RL, Kendrick ML, Nagorney DM and Farnell MB: Overall survival is increased among stage III pancreatic adenocarcinoma patients receiving neoadjuvant chemotherapy compared to surgery first and adjuvant chemotherapy: An intention to treat analysis of the National Cancer Database. Surgery 160: 1080-1096, 2016. PMID: 27522556. DOI: 10.1016/j.surg.2016.06.010

31 Stokes JB, Nolan NJ, Stelow EB, Walters DM, Weiss GR, de Lange EE, Rich TA, Adams RB and Bauer TW: Preoperative capecitabine and concurrent radiation for borderline resectable pancreatic cancer. Ann Surg Oncol 18: 619-627, 2011. PMID: 21213060. DOI: $10.1245 / \mathrm{s} 10434-010-1456-7$

32 Hackert T, Sachsenmaier M, Hinz U, Schneider L, Michalski CW, Springfeld C, Strobel O, Jager D, Ulrich A and Buchler MW: Locally advanced pancreatic cancer: Neoadjuvant therapy with folfirinox results in resectability in $60 \%$ of the patients. Ann Surg 264: 457-463, 2016. PMID: 27355262. DOI: 10.1097/SLA.0000000000001850

Received January 23, 2019

Revised February 6, 2019

Accepted February 14, 2019 